\title{
Using measured soil water contents to estimate evapotranspiration and root water uptake profiles - a comparative study
}

\author{
M. Guderle ${ }^{1,2,3}$ and A. Hildebrandt ${ }^{1,2}$ \\ ${ }^{1}$ Friedrich Schiller University, Institute for Geosciences, Burgweg 11, 07749 Jena, Germany \\ ${ }^{2}$ Max Planck Institute for Biogeochemistry, Biogeochemical Processes, Hans-Knöll-Str. 10, 07745 Jena, Germany \\ ${ }^{3}$ International Max Planck Research School for Global Biogeochemical Cycles, Hans-Knöll-Str. 10, 07745 Jena, Germany \\ Correspondence to: M. Guderle (marcus.guderle@uni-jena.de)
}

Received: 11 September 2014 - Published in Hydrol. Earth Syst. Sci. Discuss.: 29 September 2014

Revised: 11 December 2014 - Accepted: 12 December 2014 - Published: 21 January 2015

\begin{abstract}
Understanding the role of plants in soil water relations, and thus ecosystem functioning, requires information about root water uptake. We evaluated four different complex water balance methods to estimate sink term patterns and evapotranspiration directly from soil moisture measurements. We tested four methods. The first two take the difference between two measurement intervals as evapotranspiration, thus neglecting vertical flow. The third uses regression on the soil water content time series and differences between day and night to account for vertical flow. The fourth accounts for vertical flow using a numerical model and iteratively solves for the sink term. None of these methods requires any a priori information of root distribution parameters or evapotranspiration, which is an advantage compared to common root water uptake models. To test the methods, a synthetic experiment with numerical simulations for a grassland ecosystem was conducted. Additionally, the time series were perturbed to simulate common sensor errors, like those due to measurement precision and inaccurate sensor calibration. We tested each method for a range of measurement frequencies and applied performance criteria to evaluate the suitability of each method. In general, we show that methods accounting for vertical flow predict evapotranspiration and the sink term distribution more accurately than the simpler approaches. Under consideration of possible measurement uncertainties, the method based on regression and differentiating between day and night cycles leads to the best and most robust estimation of sink term patterns. It is thus an alternative to more complex inverse numerical methods. This study demonstrates that highly resolved (temporally and spatially)
\end{abstract}

soil water content measurements may be used to estimate the sink term profiles when the appropriate approach is used.

\section{Introduction}

Plants play a key role in the Earth system by linking the water and the carbon cycle between soil and atmosphere (Feddes et al., 2001; Chapin et al., 2002; Feddes and Raats, 2004; Teuling et al., 2006b; Schneider et al., 2009; Seneviratne et al., 2010; Asbjornsen et al., 2011). Knowledge of evapotranspiration and especially root water uptake profiles is key to understanding plant-soil-water relations and thus ecosystem functioning, in particular efficient plant water use, storage keeping and competition in ecosystems (Davis and Mooney, 1986; Le Roux et al., 1995; Jackson et al., 1996; Hildebrandt and Eltahir, 2007; Arnold et al., 2009; Schwendenmann et al., 2014).

For estimation of root water uptake, models are prevalent in many disciplines. Most commonly, root water uptake is applied as a sink term $S$, incorporated in the 1-D soil water flow equation (Richards equation, Eq. 1)

$$
\frac{\partial \theta}{\partial t}=\frac{\partial}{\partial z}\left[K(h)\left(\frac{\partial h}{\partial z}+1\right)\right]-S(z, t)
$$

where $\theta$ is the volumetric soil water content, $t$ is time, $z$ is the vertical coordinate, $h$ is the soil matric potential, $K(h)$ is the unsaturated soil hydraulic conductivity and $S(z, t)$ is the sink term (water extraction by roots, evaporation, etc.). The sink term profile $S(z, t)$ depends on root activity, which 
has to be known previously. Often root activity is assumed to be related to rooting profiles, represented by power laws (Gale and Grigal, 1987; Jackson et al., 1996; Schenk, 2008; Kuhlmann et al., 2012). The parameters of those rooting profile functions are cumbersome to measure in the field, and the relevance for root water uptake distribution is also uncertain (Hamblin and Tennant, 1987; Lai and Katul, 2000; Li et al., 2002; Doussan et al., 2006; Garrigues et al., 2006; Schneider et al., 2009). Therefore, assumptions have to be made in order to determine the sink term for root water uptake in soil water flow models. The lack of an adequate description of root water uptake parameters was mentioned by Gardner (1983) and is currently still an issue (Lai and Katul, 2000; Hupet et al., 2002; Teuling et al., 2006a, b). For those reasons, methods for estimating root water uptake are a paramount requirement.

Standard measurements, for instance of soil water content profiles, are recommended to be used for estimation of evapotranspiration and root water uptake at low cost, since the evolution of soil moisture in space and time is expected to contain information on root water uptake (Musters and Bouten, 2009; Hupet et al., 2002; Zuo and Zhang, 2002; Teuling et al., 2006a). Methods using these measurements are, for instance, simple water balance approaches, which estimate evapotranspiration (Wilson et al., 2001; Schume et al., 2005; Kosugi and Katsuyama, 2007; Breña Naranjo et al., 2011) and root water uptake (Clothier and Green, 1995; Coelho and Or, 1996; Hupet et al., 2002) by calculating the difference in soil water storage between two different observation times. The advantages of these simple water balance methods are the small amount of information required and the simple methodology. However, a disadvantage is that the depletion of soil water is assumed to occur only by root water uptake and soil evaporation, and soil water fluxes are negligible. This is only the case during long dry periods with high atmospheric demand (Hupet et al., 2002).

A possible alternative which allows for the consideration of vertical soil water fluxes is the inverse use of numerical soil water flow models (Musters and Bouten, 1999; Musters et al, 2000; Vrugt et al., 2001; Hupet et al., 2002; Zuo and Zhang, 2002). Root water uptake or parameters on the root water uptake function are estimated by minimizing the differences between measured soil water contents and the corresponding model results by an objective function (Hupet et al., 2002). However, the quality of the estimation depends, on the one hand, strongly on system boundary conditions (e.g., incoming flux, drainage flux or location of the groundwater table) and soil parameters (e.g., hydraulic conductivity), which are, on the other hand, notoriously uncertain under natural conditions (Musters and Bouten, 2000; Kollet, 2009). Another problem is that the applied models for soil water flow potentially ignore biotic processes. For example, Musters et al. (2000) and Hupet et al. (2002) attempted to fit parameters for root distributions in a model determining uptake profiles from water availability, whereas empirical and modeling studies suggest that adjustment of root water uptake distribution may also be from physiological adaptations (Jackson et al., 2000; Zwieniecki et al., 2003; Bechmann et al., 2014). In order to avoid this problem, Zuo and Zhang (2002) coupled a water balance approach to a soil water model, which enabled them to estimate root water uptake without the a priori estimation of root water uptake parameters.

A second option for accounting for vertical soil water flow in a water balance approach is to analyze the soil moisture fluctuation between day and night ( $\mathrm{Li}$ et al., 2002). In comparatively dry soil, Li et al. (2002) fitted third-order polynomials to the daytime- and nighttime-measured soil water content time series and calculated vertical soil water flow using the first derivative of the fitted polynomials during nighttime.

Up to now, little effort has been made to compare those different data-driven methods for estimating evapotranspiration and root water uptake profiles in temperate climates. In this paper, we compare those water balance methods we are aware of that do not require any a priori information of root distribution parameters. We used artificial data of soil moisture and sink term profiles to compare the quality of the estimates of the different methods. Furthermore, we investigated the influence of sensor errors on the outcomes, as these uncertainties can have a significant impact on both data-driven approaches and soil hydrological models (Spank et al., 2013). For this, we artificially introduced measurement errors to the synthetic soil moisture time series that are typical for soil water content measurements: sensor calibration error and limited precision.

Our results indicate that highly resolved soil water content measurements can provide reliable predictions of the sink term or root water uptake profile when the appropriate approach is used.

\section{Material and methods}

Table A1 summarizes the variable names used in this section together with their units.

\subsection{Target variable and general procedure}

The evapotranspiration $E$ consists of soil evaporation $E_{\mathrm{S}}$ and the plant transpiration $E_{\mathrm{t}}$ (Eq. 2):

$E=\left(E_{\mathrm{s}}+E_{\mathrm{t}}\right)$.

The distinction between soil evaporation and combined transpiration is not possible for any of the applied water balance methods. Therefore, the water extraction from soil by plant roots and soil evaporation is referred to as the sink term profile in the rest of the paper. The integrated sink term over 
Table 1. The abbreviation and full name of the methods for further use, overviews of the four applied data-driven methods, and the required input data.

\begin{tabular}{|c|c|c|c|}
\hline Abbreviation & Method & Method short description & Input data \\
\hline sssl & $\begin{array}{l}\text { Single-step, single-layer } \\
\text { water balance }\end{array}$ & $\begin{array}{l}\text { Water balance } \\
\text { (Breña Naranjo et al., 2011) }\end{array}$ & $\begin{array}{l}\text { Volumetric soil water content at } \\
\text { a single depth, } \\
\text { precipitation }\end{array}$ \\
\hline ssml & $\begin{array}{l}\text { Single-step, multi-layer } \\
\text { water balance }\end{array}$ & $\begin{array}{l}\text { Water balance over entire soil } \\
\text { profile (Clothier and Green, } \\
\text { 1995; Coelho and Or, 1996; } \\
\text { Hupet et al., 2002) }\end{array}$ & $\begin{array}{l}\text { Volumetric soil water content at } \\
\text { several depths, } \\
\text { precipitation }\end{array}$ \\
\hline $\mathrm{msml}$ & $\begin{array}{l}\text { Multi-step, multi-layer } \\
\text { regression }\end{array}$ & $\begin{array}{l}\text { Approach to use the short-term } \\
\text { fluctuations of soil moisture } \\
\text { (Li et al., 2002) }\end{array}$ & $\begin{array}{l}\text { Volumetric soil water content at } \\
\text { several depths, } \\
\text { precipitation }\end{array}$ \\
\hline $\mathrm{im}$ & Inverse model & $\begin{array}{l}\text { Water balance solved iteratively } \\
\text { with a numerical soil water flow } \\
\text { model (Zuo and Zhang, 2002; } \\
\text { Ross, 2003) }\end{array}$ & $\begin{array}{l}\text { Soil hydraulic parameters } \\
\text { Volumetric soil water content at } \\
\text { several depths, } \\
\text { precipitation }\end{array}$ \\
\hline
\end{tabular}

the entire soil profile results in the total evapotranspiration (Eq. 3):

$$
E(t)=\int_{z=z_{r}}^{0} S(t, z) \mathrm{d} z \rightarrow E_{j}=\sum_{i=1}^{n} S_{i, j} \cdot d_{z, i}
$$

where $z$ is the soil depth, $d_{z, i}$ is the thickness of the soil layer $i, t$ is time and $j$ is the time step. For matters of simplicity we will drop the index $j$ when introducing the estimation methods in the following.

In this study, synthetic time series of volumetric soil water content generated by a soil water flow model coupled with a root water uptake model (Sect. 2.3) were treated as measured data and are used as the basis for all methods (Sect. 2.2) estimating the sink term $\widetilde{S}(z)$, and total evapotranspiration $\widetilde{E}$. In order to investigate the influence of sensor errors, the generated time series were systematically disturbed, as shown in Sect. 2.4. Based on these estimations, we evaluate the datadriven methods on predicting evapotranspiration $\widetilde{E}$ and sink term profiles using the quality criteria given in Sect. 2.5. As the depth at which a given fraction of root water uptake occurred is often of interest in ecohydrological studies (e.g., Clothier and Green, 1999; Plamboeck et al., 1999; Ogle et al., 2004), estimated sink term profiles were compared accordingly. Specifically, we determined up to which depths 25,50 and $90 \%\left(z_{25} \%, z_{50} \%\right.$ and $\left.z_{90} \%\right)$ of water extraction takes place.

\subsection{Investigated data-driven methods for estimation of the sink term profile}

In the following we introduce the four investigated methods. They are summarized in Table 1.

\subsubsection{Single-step, single-layer (sssl) water balance}

Breña Naranjo et al. (2011) derived the sink term using time series of rainfall and changes of soil water content between two observation times (single step), based on measurements at one single soil depth (single layer). The complete water balance equation for this single-layer method is

$\widetilde{E}_{\mathrm{sss} l}=P-q-z_{\mathrm{r}} \frac{\Delta \theta}{\Delta t}$,

where $z_{\mathrm{r}}$ is the active rooting depth, which is also the depth of the single soil layer, and is taken equal to the measurement depth of volumetric soil water content, $\theta . \Delta t$ indicates the length of the considered single time step. $P$ is the rainfall and $q$ the percolation out of the soil layer during the same time step. When rainfall occurs, infiltration as well as soil water flow takes place. It is assumed that percolation occurs only during this time and persists only up to several hours after the rainfall event (Breña Naranjo et al., 2011). Since the percolation flux is unknown, the methods cannot be applied during these wet times. During dry periods, $q$ is set to zero and Eq. (4) simplifies to Eq. (5) (Breña Naranjo et al., 2011):

$\widetilde{E}_{\mathrm{sss} 1}=z_{\mathrm{r}} \frac{\Delta \theta}{\Delta t}$.

We applied Eq. (5) to estimate evaporation (in the singlelayer method equal to the sink term) from artificial soil water contents at $30 \mathrm{~cm}$. Required input information is thus only time series of soil water content and active rooting depth $z_{\mathrm{r}}$. Additionally, rainfall measurements are required to select dry periods, where no percolation occurs. These could start several hours up to several days after a rainfall event (Breña Naranjo et al., 2011), and the exact timing depends on the 
amount of rainfall and the site-location parameters like soil type and vegetation. In this study we waited until $24 \mathrm{~h}$ after the end of the precipitation event before applying the model.

\subsubsection{Single-step, multi-layer (ssml) water balance}

This method is similar to the sssl method introduced above. It calculates the sink term based on two observation times (single step), but is extended to several measurement depths (multi-layer). The water balance during dry periods of each layer is the same as in Eq. (5), and uptake in individual layers is calculated by neglecting vertical soil water fluxes and therefore assuming that the change in soil water content is only caused by root water uptake (Hupet et al., 2002):

$\widetilde{S}_{\mathrm{ssml}, i}=d_{z, i} \frac{\Delta \theta_{i}}{\Delta t}$,

where $\widetilde{S}_{\mathrm{ssml}, i}$ is the estimated sink term in soil layer $i, \Delta \theta_{i}$ is the change in soil water content in the soil layer $i$ over the single time step $(\Delta t)$ and $d_{z, i}$ is the thickness of the soil layer $i$. Actual evapotranspiration $\left(E_{\mathrm{ssml}}\right)$ is calculated by summing up $\widetilde{S}_{\mathrm{ssml}, i}$ over all depths in accordance with (Eq. 3). The application of the ssml method is restricted to dry periods. It requires time series of volumetric soil water content and rainfall measurements as input to select dry periods.

\subsubsection{Multi-step, multi-layer $(\mathrm{msml})$ regression}

The third method derives actual evapotranspiration and sink term profiles from diurnal fluctuation of soil water contents (Li et al., 2002). It uses a regression over multiple time steps (multi-step) and can be applied at several measurement depths (multi-layer).

During daytime, evapotranspiration leads to a decrease in volumetric soil water content. This extraction of soil water extends over the entire active rooting depth. Additionally, soil water flow occurs both at night and during the daytime (Khalil et al., 2003; Verhoef et al., 2006; Chanzy et al., 2012), following potential gradients in the soil profile. Thus, during dry weather conditions, the time series of soil water content shows a clear day-night signal (Fig. 1). We split up the time series by fitting a linear function to each day and night branch of the time series. The onset of transpiration is mainly defined by opening and closure of plant stomata, which is according to the supply of solar energy (Loheide, 2008; Maruyama and Kuwagata, 2008; Sánchez et al., 2013), usually 1 or $2 \mathrm{~h}$ after sunrise or before sunset (Lee, 2009).

Here, the basic assumption is that the soil water flow does not change significantly between day and night (Fig. S1 in the Supplement). The slope of the fitted linear functions gives the rate of root water extraction and vertical flow. This can also be shown mathematically by disassembling the Richards equation (Eq. 1) in vertical flow (subscript flow) and sink term (subscript extr) (Eq. 7), whereas the change in soil water content over time $(\partial \theta / \partial t)$ integrates both fluxes:

$$
\frac{\partial \theta}{\partial t}=\left.\frac{\partial \theta}{\partial t}\right|_{\text {flow }}+\left.\frac{\partial \theta}{\partial t}\right|_{\text {extr }}=m_{\text {tot }},
$$

where $m_{\text {tot }}$ corresponds to the slope of the fitted linear function for the day or night branch. Assuming that evapotranspiration during the night is negligible, the slope for the night branch is entirely due to soil water flow. During the day, uptake processes and soil water flow act in parallel:

day : $\quad m_{\text {tot }}=m_{\text {flow }}+m_{\text {extr }}$,

night $: \quad m_{\text {tot }}=m_{\text {flow }}$.

The sink term can be calculated from Eq. (8a), assuming that $m_{\text {flow }}$ can be estimated from Eq. (8b) and using the average of the antecedent and the preceding night. A similar procedure has previously been applied in diurnal groundwater table fluctuations (Loheide, 2008). Also the extraction will be overestimated if day and night fluxes are not separately considered. With the soil layer thickness of the respective layer $i\left(d_{z, i}\right)$ taken into account, the mean daily sink term of soil layer $i\left(\widetilde{S}_{\mathrm{msml}, i}\right)$ is obtained:

$\widetilde{S}_{\mathrm{msm}, i}=\left(m_{\mathrm{tot}, i}-\bar{m}_{\mathrm{flow}, i}\right) \cdot d_{z, i}$.

Since a diurnal cycle of soil moisture is only identifiable up to a time interval of $12 \mathrm{~h}$, the regression method is limited to a minimum measurement frequency of $12 \mathrm{~h}$. Furthermore, as rainfall causes changes of soil water content and blurs the diurnal signal, the $\mathrm{msml}$ regression is only applicable during dry periods. Time series of soil water content and rainfall measurements to select dry periods are required as input.

\subsubsection{Inverse model (im)}

The fourth approach is the most complex. The inverse model (im) estimates the average root water uptake by solving the Richards equation (Eq. 1) and iteratively searching for the sink term profile which produces the best fit between the numerical solution and measured values of soil moisture content (Zuo and Zhang, 2002). The advantage of this method is the estimation of root water uptake without the a priori estimation of rooting profile function parameters, since they are highly uncertain, as elucidated in the Introduction. We implemented the inverse water balance approach after Zuo and Zhang (2002) with the Fast Richards Solver (Ross, 2003), which is available as Fortran 90 code. We modified the original method by changing the convergence criterion. In the following section, we first introduce the iterative procedure as proposed by Zuo and Zhang (2002) and then explain the modification which we made. 
The iterative procedure by Zuo and Zhang (2002) runs the numerical model over a given time step $(\Delta t)$ in order to estimate the soil water content profile $\widetilde{\theta}_{i}^{(v=0)}$ at the end of the time step, and assuming that the sink term $\left(\widetilde{S}_{\mathrm{im}, i}^{(v=0)}\right)$ is zero over the entire profile. Here $\sim$ depicts the estimated values at the respective soil layer $i$, and $v$ indicates the iteration step. Next, the sink term profile $\widetilde{S}_{\mathrm{im}, i}^{(v=1)}$ is set equal to the difference between previous approximation $\widetilde{\theta}_{i}^{(v=0)}$ and measurements $\theta_{i}$ while accounting for soil layer thickness and the length of the time step for units.

In the following iterations, $\widetilde{S}_{\mathrm{im}, i}^{(v)}$ is used with the Richards equation to calculate the new soil water contents $\widetilde{\theta}_{i}^{(v)}$. The new average sink term $\widetilde{S}_{\mathrm{im}, i}^{(v+1)}$ is then determined with Eq. (10):

$\widetilde{S}_{\mathrm{im}, i}^{(v+1)}=\widetilde{S}_{\mathrm{im}, i}^{(v)}+\frac{\widetilde{\theta}_{i}^{(v)}-\theta_{i}}{\Delta t} \cdot d_{z, i}$.

This iteration process continues until a specified decision criterion $\varepsilon_{\mathrm{ZZ}}$ is reached:

$\varepsilon_{\mathrm{ZZ}} \geq \frac{1}{n} \sum_{i=1}^{n}\left[\frac{\widetilde{\theta}_{i}^{(v)}-\theta_{i}}{\theta_{i}}\right]^{2}$,

where $n$ is the number of soil layers in the soil column.

Since $\varepsilon_{Z Z}$ is a normalized root-mean-square error over depth, good and poor estimations cancel between layers. This leads to termination of the iterative procedure even if the estimation of the sink term is very poor in several layers. We therefore propose a slightly adapted termination process which applies to separate soil layers as follows. The estimation of the sink term in general is applied as proposed by Zuo and Zhang (2002):

1. Calculate the difference between the estimated and measured soil water content (Eq. 12) and compare the change in this difference to the difference of the previous iteration (Eq. 13):

$$
e_{i}^{(v)}=\left|\theta_{i}-\widetilde{\theta}_{i}^{(v)}\right|
$$

$$
\varepsilon_{\mathrm{GH}, i}^{(v)}=e_{i}^{(v-1)}-e_{i}^{(v)} .
$$

2. In soil layers where $\varepsilon_{\mathrm{GH}}^{(v)}<0$, set the root water uptake rate back to the value of the previous iteration $\left(\widetilde{S}_{\mathrm{im}, i}^{(v+1)}=\right.$ $\left.\widetilde{S}_{\mathrm{im}, i}^{(v-1)}\right)$, since the current iteration was no improvement. Only if $\varepsilon_{\mathrm{GH}, i}^{(v)} \geq 0$, go to step (3). This prevents acceptance of the estimated sink term $\widetilde{S}_{\mathrm{im}, i}^{(v)}$ even if it leads to a worse fit than the previous iteration.
3. If $e_{i}^{(v)}>1 \times 10^{-4}$, calculate $\widetilde{S}_{\mathrm{im}, i}^{(v+1)}$ according Eq. (10); otherwise the current iteration sink term $\left(\widetilde{S}_{\mathrm{im}, i}^{(v+1)}=\right.$ $\left.\widetilde{S}_{\mathrm{im}, i}^{(v)}\right)$ is retained, as it results in a good fit between estimated and measured soil water contents.

The iteration process continues until the convergence criterion $\varepsilon_{\mathrm{GH}}^{(v)}$ (Eq. 13) no longer changes between iterations (i.e., all layers have reached a satisfactory fit), or after a specified number of iterations (we chose 3000).

Besides the soil water content measurements and the rainfall, the input information required is the soil hydraulic parameters.

\subsection{Generation of synthetic reference data}

We used synthetic time series of volumetric soil water content with a measurement frequency of 1, 3, 6, 12 and $24 \mathrm{~h}$. The time series of soil water content as well as the sink term profiles were generated with a Soil water flow model (Fast Richards Solver (Ross, 2003), same as used in Sect. 2.2 for the im). These were treated as measured data and are used as the basis for all methods. The synthetic data are based on meteorological and soil data from the Jena Biodiversity Experiment (Roscher et al., 2011). Root water uptake was calculated using a simple macroscopic root water uptake model which uses an exponential root distribution with water stress compensation ( $\mathrm{Li}$ et al., 2001). Soil evaporation is taken as $20 \%$ of total evapotranspiration.

The soil profile is based on the Jena Experiment, both in terms of measurement design and soil properties. The model was set up for a one-dimensional homogeneous soil profile $220 \mathrm{~cm}$ deep. Measurement points were set at depths of 15 , $30,60,100,140,180$ and $220 \mathrm{~cm}$. The spatial resolution of the soil model is according to the measurement points 15,15 , $30,40,40,40$ and $40 \mathrm{~cm}$. The advantage of the applied soil water flow model is that the water fluxes are calculated with the matrix flux potential (Kirchhoff transformation), which allows for spatial discretization with large nodal spacing (Ross, 2006). We used a maximum rooting depth of $140 \mathrm{~cm}$, with $60 \%$ of root length density located in the top $15 \mathrm{~cm}$ of the root zone, which corresponds to mean values measured on the field site (Ravenek et al., 2014). We used van Genuchten soil hydraulic parameters (van Genuchten, 1980) derived from the program ROSETTA (Schaap et al., 2001) based on the texture of a silty loam: $\theta_{\mathrm{s}}=0.409\left(\mathrm{~cm}^{3} \mathrm{~cm}^{-3}\right)$, $\theta_{\mathrm{r}}=0.069\left(\mathrm{~cm}^{3} \mathrm{~cm}^{-3}\right), K_{\text {sat }}=1.43 \times 10^{-6}\left(\mathrm{~m} \mathrm{~s}^{-1}\right), \alpha=0.6$ $\left(\mathrm{m}^{-1}\right)$ and $n_{\mathrm{VG}}=1.619(-)$.

Upper boundary conditions are derived from measured precipitation and potential evapotranspiration calculated after Penman-Monteith (Allen et al., 1998) from measurements of the climate station at the experimental site (Weather Station Saaleaue, Max Planck Institute for Biogeochemistry, http://www.bgc-jena.mpg.de/wetter/). The weather data used have a measurement resolution of $10 \mathrm{~min}$. Before applying evapotranspiration and rainfall as input data to generate the 


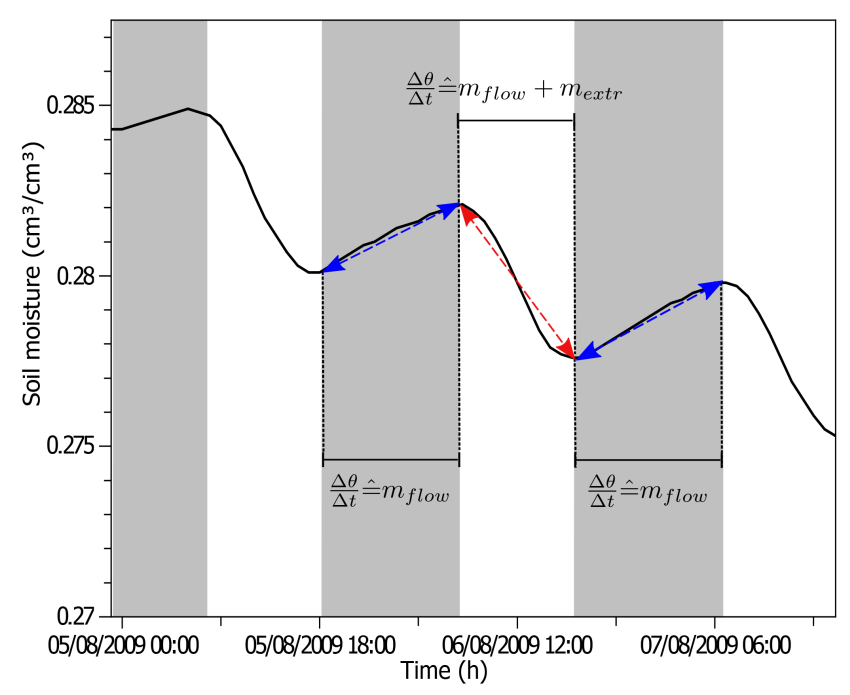

Figure 1. Short-term fluctuations in soil moisture in $15 \mathrm{~cm}$ depth during August 2009, showing the rewetting of soil at nighttime (blue line) and the water extraction during the day (red line); dashed lines depict the change between times with soil water extraction (white) and rewetting of soil (grey).

synthetic reference soil moisture and root water uptake data, both data sets were aggregated to the temporal resolutions applied for the reference run $(1 \mathrm{~h})$. Soil moisture and root water uptake were generated with the same temporal resolution. When translating the evapotranspiration into sink term profiles (four-digit precision), rounding errors introduce a small inaccuracy. Thus, the sum of the sink term in the reference run deviates by $0.02 \%$ compared to the original evapotranspiration.

The lower boundary is given by the groundwater table, which fluctuates around $-200 \mathrm{~cm}$ at the field site, but was set to constant head for simplification. Initial conditions are taken as the equilibrium (no flow) hydraulic potential profile in the soil.

We run the model with precipitation data from the field site for the year 2009, starting on 1 January to calculate time series of soil water content and the root water uptake up to September 2009. The atmospheric boundary conditions during the growing season are shown in Fig. 2a as daily values. For testing the methods, we used the period from 26 July to 28 August 2009, which covers a dry period with little rainfall (Fig. 2, black-outlined area). The times were chosen to cover a representative but dry period during the growing season and to guarantee a warm-up phase for the soil model.

The described forward simulation produces time series of soil water contents and root water uptake. Soil water content time series were used instead of measured data (synthetic measurements) as input for the investigated methods, while evapotranspiration and sink term profiles were used to evaluate them, based on the quality criteria described in Sect. 2.5.

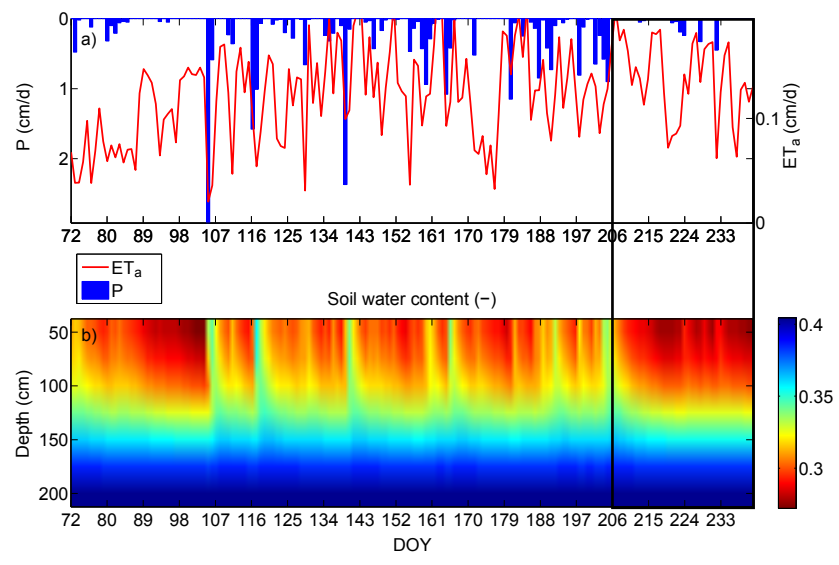

Figure 2. Actual evapotranspiration $\left(\mathrm{ET}_{\mathrm{a}}\right)$ and precipitation $(\mathrm{P})$ $\left(\mathrm{cm} \mathrm{day}^{-1}\right)$ in the growing season (from March 2009 to September 2009) (a) and synthetic time series of soil water content (b) with daily resolution.

\subsection{Influence of soil moisture sensor uncertainty}

Data-driven methods are as good as their input data. Therefore, we investigate and quantify the influence of common uncertainties of soil moisture sensor measurements on the estimation of sink term profiles. Sensor performance is usually characterized by three criteria, namely the accuracy, the precision and the resolution. The correctness of a measurement is described by the accuracy and for water content sensors depends greatly on the soil-specific calibration. Repeatability of many single measurements is referred to as precision, while the resolution describes the fineness of a measurement.

In this paper, we investigated the uncertainty of the applied methods stemming from calibration error (accuracy) and precision. For this we superimposed the original synthetic soil water content measurements generated in Sect. 2.3 with artificial errors. Three types of errors were implemented, as follows. (i) Precision error: the time series for each soil layer were perturbed with Gaussian noise of zero mean and standard deviation of $0.067 \mathrm{vol} . \%$ corresponding to a precision of $0.2 \mathrm{vol} . \%$; (ii) calibration error: the perturbed time series were realigned along a new slope, which pivoted around a random point within the measurement range and a random intercept within \pm 1.0 vol. \%; (iii) calibration and precision: perturbed series were created as a random combination of (i) and (ii), which is a common case in field studies (Spank et al., 2013). Errors were applied independently to all soil depths, and 100 new time series were created for each of the error types. We determined the quality of the estimation methods using the median of 100 ensemble simulations with the 100 perturbed input time series. The values for the applied calibration uncertainty and precision are taken from the technical manual of the IMKO TRIME ${ }^{\odot}$-PICO32 soil moisture sensor (http://www.imko.de/en/products/soilmoisture/ soil-moisture-sensors/trimepico32). 
A common procedure with environmental measurements for dealing with precision errors is smoothing of the measured time series (Li et al., 2002; Peters et al., 2013), which we also reproduced by additionally applying a moving average filter on the disturbed soil moisture time series.

\subsection{Evaluation criteria}

A successful model should be able to reproduce the first and second moment of the distribution of the observed values (Gupta et al., 2009), and we used a similar approach to assess the quality of the methods for estimating the total evapotranspiration and the sink term profiles. The first and the second moment refer to the mean and the standard deviation. Additionally, the correlation coefficient evaluates whether the model is able to reproduce the timing and the shape of observed time series. To compare the applicability and the quality of the four methods, we use three performance criteria suggested by Gupta et al. (2009): (i) the correlation coefficient $(R)$, (ii) the relative variability measure (RV) and (iii) the bias $(b)$, which are described in this section. The comparison is based on daily values.

First, we use $R$ to estimate the strength of the linear correlation between estimated $(\sim)$ and synthetic values:

$R=\frac{\operatorname{Cov}(\tilde{x}, x)}{s_{x} \cdot s_{\tilde{x}}}$,

where "Cov" is the covariance of estimated and observed (synthetic) values, and $s_{x}$ and $s_{\widetilde{x}}$ are the standard deviations of synthetic and estimated values, respectively. The variable $x$ stands for any of the variables of interest, such as total evapotranspiration or $z_{25} \%$. $R$ ranges between -1 and +1 . The closer $R$ is to 1 , the better the estimate.

Second, we use the relative variability in estimated and synthetic data (RV) to determine the ability of the particular method to reproduce the observed variance (Gupta et al., 2009):

$\mathrm{RV}=\frac{s_{\tilde{x}}}{s_{x}}$.

RV values around 1 indicate a good estimation procedure.

Third, we use the relative bias $(b)$ to describe the mean systematic deviation between estimated $\left({ }^{\sim}\right.$ ) and observed (synthetic) values, which is never captured by $R$ :

$b=\frac{\overline{\tilde{x}}-\bar{x}}{\bar{x}} \cdot 100(\%)$,

where $\overline{\tilde{x}}$ and $\bar{x}$ are the means of the estimated and synthetic data, respectively. The best model performance is reached if the bias is close to zero.

\section{Results}

In total, we compared synthetic evapotranspiration rates from 33 consecutive days in July/August 2009. Evapotranspiration could not be estimated for days with rainfall using either the sssl or ssml method, nor with the msml regression. Therefore, we excluded all days with rainfall from the analysis for all considered methods. In Sect. 3.1 and 3.2 we first consider the performance of the estimation methods on undisturbed synthetic time series, i.e., we ignore measurement errors or assume they do not exist. The influence of measurement errors is investigated in Sect. 3.3.

\subsection{Evapotranspiration derived by soil water content measurements}

The performance of the data-driven methods depends strongly on the complexity of the respective method, which substantially increases with a higher degree of complexity. However, the influence of the measurement frequency differs considerably among the four methods.

The im predicted the daily evapotranspiration for a measurement frequency of $12 \mathrm{~h}$ with a very small relative bias of $0.89 \%$, which is the best value of all investigated methods. Additionally, the im reaches the best $R$ value $(R=0.99)$ for all measurement frequencies (Table 2 ), and closely follows the $1: 1$ line between synthetic and estimated evapotranspiration (Fig. 3a, b). However, the RV and the relative bias indicate better prediction with decreasing measurement frequency.

The second-best method is the msml regression, in particular when applied for high temporal resolution measurements ( 1 and $3 \mathrm{~h})$. There, the bias is comparatively small $( \pm 20 \%)$ and the correlation between synthetic (observed) and estimated values is relatively high $(R=0.58$ and $R=$ 0.71 for 1 and $3 \mathrm{~h}$ resolution, respectively). Also, the msml results match the $1: 1$ line well between synthetic and estimated evapotranspiration (Fig. 3a, b).

The sssl and the ssml methods show a weaker performance compared to the more complex im and msml methods. Neither of them follows the $1: 1$ line well between synthetic and estimated evapotranspiration (Fig. 3a, b). Regardless, they could reproduce the synthetic evapotranspiration with a relatively high linear correlation (Table 2), and comparable bias to the regression method, in particular for the range of intermediate measurement frequencies. However, values for the RV are comparatively large, in particular for the ssml method. Interestingly, the model performance criteria of the simpler sssl method show only minor differences between the particular temporal resolutions, and overall the sssl method performs better than the ssml method. Note that both water balance methods (sssl and ssml) overestimate the evapotranspiration at the beginning of the study period (Fig. 3c, d), which was marked by greater vertical flow between top soil and deeper soil due to preceding rainfall events.

Our results also show that less complex data-driven methods also perform better at higher temporal resolution (1 and $3 \mathrm{~h}$ ), except for the ssml method. In contrast, the im is better at predicting evapotranspiration when a coarse measurement 
Table 2. Comparison of the model performance of the four data-driven methods for reproducing daily evapotranspiration for the particular time resolution of soil moisture measurements. The model performance is expressed as correlation coefficient $R$, relative variability in simulated and reference values (RV), and relative bias (b) for the period 25 July-26 August 2009. Days on which rainfall occurs were excluded for the data analysis.

\begin{tabular}{lccccccccccccr}
\hline & \multicolumn{3}{c}{$\begin{array}{c}\text { Single-step, single- } \\
\text { layer water balance }\end{array}$} & \multicolumn{3}{c}{$\begin{array}{c}\text { Single-step multi- } \\
\text { layer water balance }\end{array}$} & \multicolumn{2}{c}{$\begin{array}{c}\text { Multi-step, multi- } \\
\text { layer regression }\end{array}$} & \multicolumn{3}{c}{$\begin{array}{c}\text { Inverse } \\
\text { model }\end{array}$} \\
\hline$\Delta t(\mathrm{~h})$ & $R$ & $\mathrm{RV}$ & $b(\%)$ & $R$ & $\mathrm{RV}$ & $b(\%)$ & $R$ & $\mathrm{RV}$ & $b(\%)$ & $R$ & $\mathrm{RV}$ & $b(\%)$ \\
\hline 1 & 0.77 & 1.51 & -38.6 & 0.64 & 3.32 & 54.2 & 0.58 & 1.54 & -22.9 & 0.99 & 0.78 & -41.5 \\
3 & 0.75 & 1.54 & -38.6 & 0.66 & 3.37 & 46.8 & 0.71 & 1.03 & 20.3 & 0.99 & 0.97 & -18.2 \\
6 & 0.75 & 1.69 & -35.9 & 0.67 & 3.52 & 36.4 & 0.78 & 1.87 & 86.5 & 0.99 & 1.03 & -7.6 \\
12 & 0.75 & 1.44 & -38.6 & 0.70 & 3.49 & 37.1 & 0.85 & 4.22 & 202.4 & 0.99 & 1.04 & 0.89 \\
24 & 0.58 & 1.76 & -37.3 & 0.53 & 3.72 & 26.4 & - & - & - & 0.99 & 1.11 & 3.5 \\
\hline
\end{tabular}
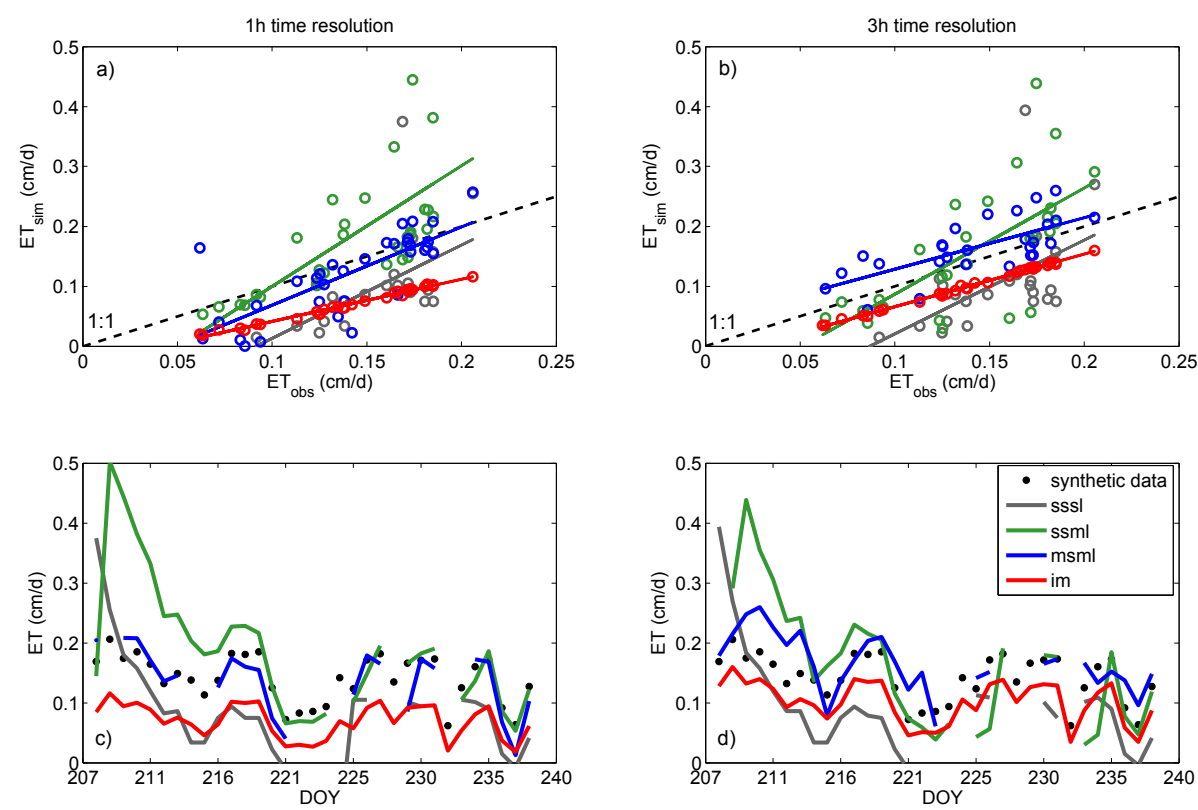

Figure 3. Top: comparison of synthetic $\left(\mathrm{ET}_{\mathrm{obs}}\right)$ and estimated $\left(\mathrm{ET}_{\mathrm{sim}}\right)$ values of daily evapotranspiration for hourly (a) and 3-hourly $(\mathbf{b})$ observation intervals of soil water content measurements. Bottom: comparison of synthetic and estimated time series of daily evapotranspiration (ET) for hourly (c) and 3-hourly (d) observation intervals of soil water content measurements (25 July to 26 August 2009). Missing values are times when rainfall and percolation appeared. An estimation of evapotranspiration was not possible with the single-step, single-layer (sssl) water balance; the single-step, multi-layer (ssml) water balance; or the multi-step, multi-layer (msml) regression for these days.

frequency is used. Further, the results indicate that the estimated actual evapotranspiration becomes more accurate with increasing model intricacy, and with vertical flow accounted for.

\subsection{Root water uptake profiles estimated with three different data-driven methods}

The ssml, msml and im method appropriate for determining root water uptake profiles by inclusion of all available measurements over depth. Table 3 summarizes the model applicability to estimate the depths at which 25,50 and $90 \%$ of water extraction occurs (later stated as $z_{25} \%, z_{50} \%$ and $z_{90} \%$ ). Here, we used the standard deviation $s_{\tilde{x}}$ instead of the relative variability to evaluate the observed variance. This criterion was chosen because the standard deviation of the synthetic reference values is approximately zero and thus the RV is increasing, which is not practical for the method evaluation. The criteria are shown for the respective best achieved model performance $(1 \mathrm{~h}-\mathrm{ssml}$ and $\mathrm{msml} ; 24 \mathrm{~h}-\mathrm{im})$.

Again, the quality of predicting the sink term distribution depends on the method complexity and increases with increasing complexity. The most complex im delivers the best prediction of sink term distribution for a temporal resolution of $24 \mathrm{~h}$. The depth above which $50 \%$ of water extraction occurs $\left(z_{50} \%\right)$ could be predicted with a bias of less than $2 \%$ (Table 3 ) and for $z 90 \%$; the relative bias increased only 
Table 3. Comparison of model performance for reproducing the sink term profile (single-step, multi-layer water balance; multi-step, multilayer regression; and inverse model). Depths where 25, 50 and $90 \%$ water extraction occurs were regarded. Mean synthetic (syn.) depth and mean estimated (est.) depth describe the mean depth over 33 days where water extraction occurs. $b$ is the relative bias and $\widetilde{s}$ is the standard deviation of the estimated values. Larger width of the black arrow denotes higher accuracy of the model results.

\begin{tabular}{|c|c|c|c|c|c|c|c|c|c|}
\hline \multirow{2}{*}{$\begin{array}{l}\text { Time resolution } \\
\text { of measurements }\end{array}$} & \multicolumn{3}{|c|}{$\begin{array}{l}\text { Single-step, multi- } \\
\text { layer water balance } 1 \mathrm{~h}\end{array}$} & \multicolumn{3}{|c|}{$\begin{array}{l}\text { Multi-step, multi- } \\
\text { layer regression } 1 \mathrm{~h}\end{array}$} & \multicolumn{3}{|c|}{$\begin{array}{c}\text { Inverse } \\
\text { model } 24 \mathrm{~h}\end{array}$} \\
\hline & $z_{25} \%$ & $z_{50 \%}$ & $z_{90 \%}$ & $z_{25 \%}$ & $z_{50 \%}$ & $z_{90 \%}$ & $z_{25} \%$ & $z_{50 \%}$ & $z_{90 \%}$ \\
\hline Mean syn. depth $(\mathrm{cm})$ & 8.1 & 17.1 & 55.6 & 8.1 & 17.1 & 55.6 & 8.1 & 17.1 & 55.6 \\
\hline Mean est. depth $(\mathrm{cm})$ & 10.8 & 28.5 & 101.9 & 9.7 & 13.9 & 63.8 & 8.2 & 17.3 & 57.3 \\
\hline$b(\%)$ & 33 & 74 & 83 & -14 & -21 & 15 & 0.75 & 1.05 & 2.97 \\
\hline$\widetilde{s}$ & 4.07 & 12.31 & 57.89 & 1.69 & 4.01 & 25.83 & 1.81 & 4.08 & 68.26 \\
\hline
\end{tabular}

slightly to approximately $3 \%$. Indeed, these comparatively accurate results are to be expected due to the two intrinsic assumptions: (1) the required soil hydraulic parameters for the implemented soil water flow model are exactly known, and (2) the measurement uncertainty of the soil sensors is zero.

The regression method ( $\mathrm{msml})$ also delivers good estimations of sink term profiles over the entire soil column (Table 3 and Fig. 4), although it manages without any intrinsic assumptions. Figure 4 shows that the msml regression overestimates the sink term at the intermediate depths. The maximum relative bias is about $-21 \%$ at $750 \%$. Overall, the $\mathrm{msml}$ regression is applicable for determining the mean sink term distribution with an acceptable accuracy.

The ssml-estimated sink terms correspond only weakly to the synthetic ones, and the relative bias is lowest for $z 25 \%$ with $33 \%$ but increases strongly for $z 50 \%$ and $z 90 \%$ (Table 3). Moreover, the standard deviations of the predictions are substantial at most measurement depths (Table 3, Fig. 4). Because of these large variations in sink term distribution, the prediction of sink term profiles becomes imprecise. Thus for the chosen simulation experiment, the ssml method is not applicable for deriving the sink term from soil water content measurements.

\subsection{Influence of soil moisture sensor uncertainty on root water uptake estimation}

We only evaluated the influence of measurement errors for two methods (msml and im). The single-layer approach was omitted since it does not allow for estimation of the sink term profile, and ssml was omitted since the estimation of the sink term profile was already inappropriate when ignoring measurement errors (see Sect. 3.2).

The influences of soil moisture sensor uncertainties differ considerably among the investigated methods. The msml method predicted the median daily evapotranspiration with precision uncertainty, calibration uncertainty and a combination of both reasonably well (Fig. 5). For all three types of uncertainty, the correlation between synthetic (observed)

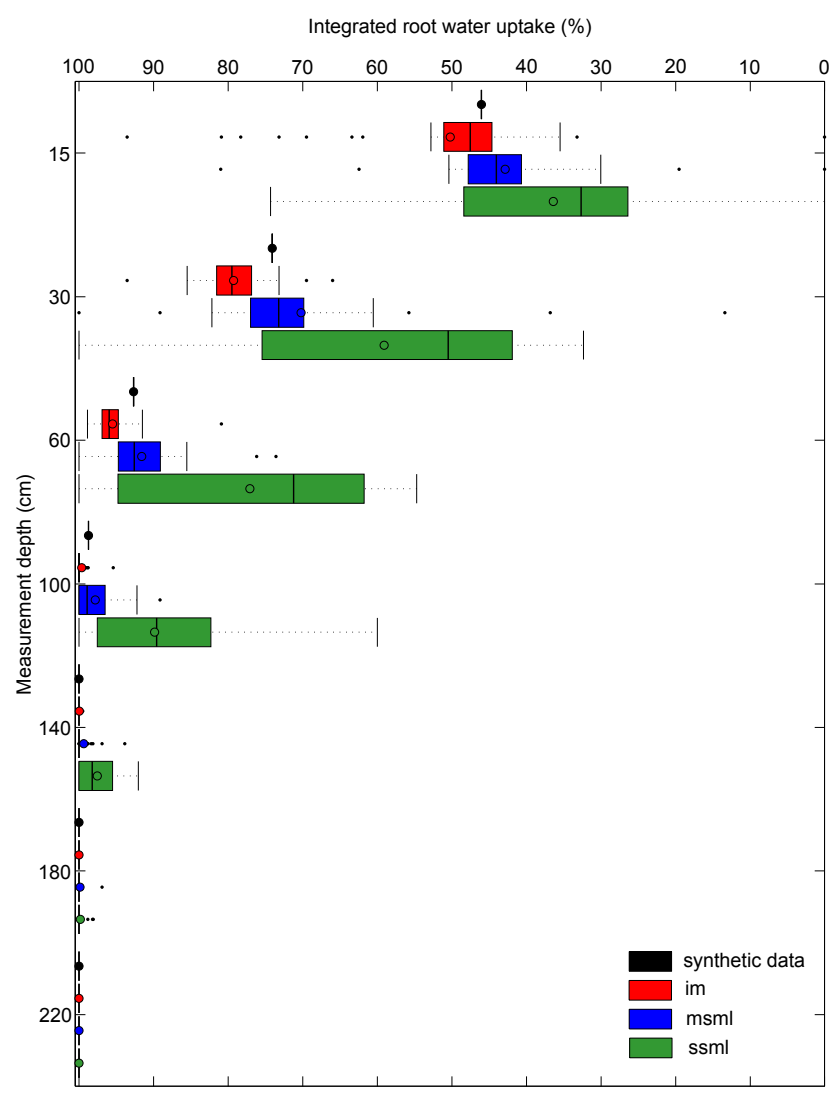

Figure 4. Box plots of the estimated daily percentage of integrated sink term. Colors are assigned as follows: synthetic values are black, the im is red, the msml regression is blue and the ssml water balance is green. The percentage of integrated sink term is shown for all measurement locations over the soil column. The circles show the mean values; the vertical line depicts the median and the 25 and $75 \%$ percentile. Values are given for the respective underlying time resolution which achieved the best results according to Table 3 (ssml - $1 \mathrm{~h}$; msml - $1 \mathrm{~h}$; im - 24h). 
Table 4. Comparison of the model performance with considering soil moisture measurement uncertainties for the msml regression and the im for reproducing daily evapotranspiration and the mean depths where 25,50 and $90 \%$ water extraction occurs. The model performance is expressed as correlation coefficient $(R)$, relative variability in simulated and reference values (RV) and relative bias $(b)$ for the period 25 July to 26 August 2009. The precision uncertainty is abbreviated as prec err, the calibration uncertainty as cali err, and the combined uncertainty as com err. The relative bias for reproducing evapotranspiration is abbreviated as $b_{\mathrm{ET}}$, and is abbreviated as $\mathrm{b}_{25} \%$, $\mathrm{b}_{50 \%}$ and b $90 \%$ for reproducing mean depths where 25,50 and $90 \%$ water extraction occurs, respectively.

\begin{tabular}{lllllll}
\hline $\begin{array}{l}\text { Time resolution } \\
\text { of measurements }\end{array}$ & \multicolumn{3}{c}{$\begin{array}{c}\text { Multi-step, multi-layer regression } \\
\text { 1 h }\end{array}$} & \multicolumn{3}{c}{$\begin{array}{c}\text { Inverse model } \\
24 \mathrm{~h}\end{array}$} \\
\hline Criterion & prec err & cali err & com err & prec err & cali err & com err \\
\hline$R$ & 0.90 & 0.89 & 0.91 & -0.027 & 0.847 & -0.054 \\
RV & 1.35 & 1.50 & 1.35 & 1.51 & 1.25 & 1.85 \\
Median bias $b_{\text {ET }}(\%)$ & -6.2 & -4.9 & -6.1 & -10.3 & 498.1 & 483.3 \\
Median bias $b_{25 \%}(\%)$ & 19.6 & 3.6 & 19.5 & 25.2 & 531.1 & 405.1 \\
Median bias $b_{50 \%}(\%)$ & 28.0 & 5.4 & 27.7 & 42.0 & 622.4 & 659.1 \\
Median bias $b_{90 \%}(\%)$ & 80.8 & 27.7 & 84.7 & 128.5 & 757.6 & 569.0 \\
\hline
\end{tabular}

and estimated values is relatively high (around $R=0.9$, Table 4). Also, with respect to the median relative bias (\%), the three cases differ only marginally $(|b|=7 \%$, Table 4$)$. Interestingly, the calibration uncertainty showed the lowest impact on the predicted evapotranspiration, with a median bias of about $-5 \%$ for the respective 100 ensemble calculations (Fig. 5).

Additionally, the bias is also used to compare the predicted relative water extraction depths $\left(z_{25} \%, z_{50} \%\right.$ and $\left.z_{90} \%\right)$ (Fig. 6). The uncertainty caused by the calibration of the sensor shows the least differences to the observed values below $10 \%$. These results are similar to those from simulations with soil moisture without any introduced measurement uncertainty. Further, the uncertainties caused by the precision of the sensors have the highest impact on predicted root water uptake patterns. It turns out that the relative uncertainty increases with increasing depth (decreasing sink term or rather water extraction, Fig. 6a).

Interestingly, the im shows worse model performances than the msml regression for all three types of uncertainty. Although, the predicted evapotranspiration from soil moisture with precision uncertainty is close to the observed values (Fig. 5), it differs around days when rainfall occurs (DOY 225, 230 and 234). This results in underestimation of evapotranspiration during these times and a weak correlation (Table 4), but an acceptable relative bias of about $-10 \%$. In contrast, for the calibration uncertainty it is the other way around. Here, the correlation is relatively high $(R=0.85)$ but evapotranspiration is greatly overestimated $(b=498 \%)$. A combination of both uncertainty sources does not further increase the overall error, but does combine both weaknesses to an overall poor estimation (Table 4).

The sensitivity to the type of uncertainty concerning prediction of sink term patterns is shown in Fig. $6 \mathrm{~b}$ and Table 4. Similar to the msml regression, the im is able to handle uncertainties in sensor precision to predict root water uptake
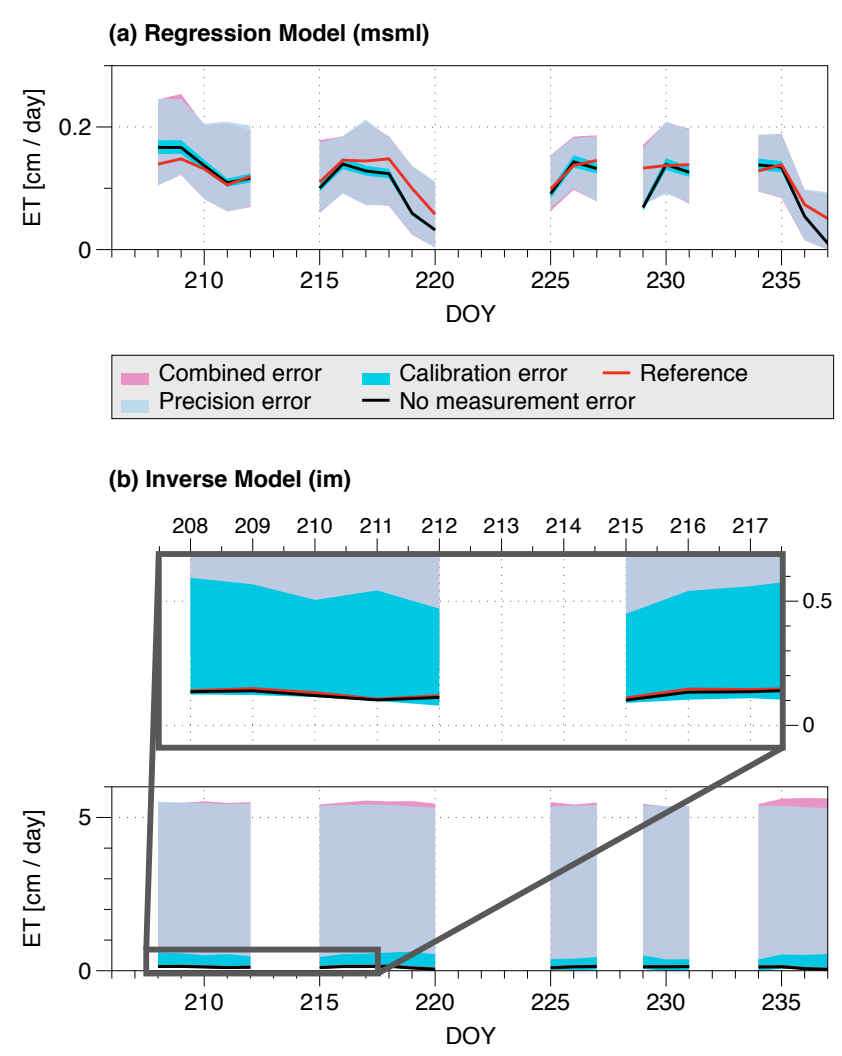

Figure 5. Influence of soil moisture uncertainty on evapotranspiration estimated with the $\mathrm{msml}$ regression model (a) and the im (b). The red line is the evapotranspiration from the synthetic data (Reference). The colored bands indicate the $95 \%$ confidence intervals.

depths, whereas uncalibrated sensors lead to considerable increases in relative bias. Overall, the simpler msml regression method shows a higher robustness against measurement uncertainties than the more complex im. 

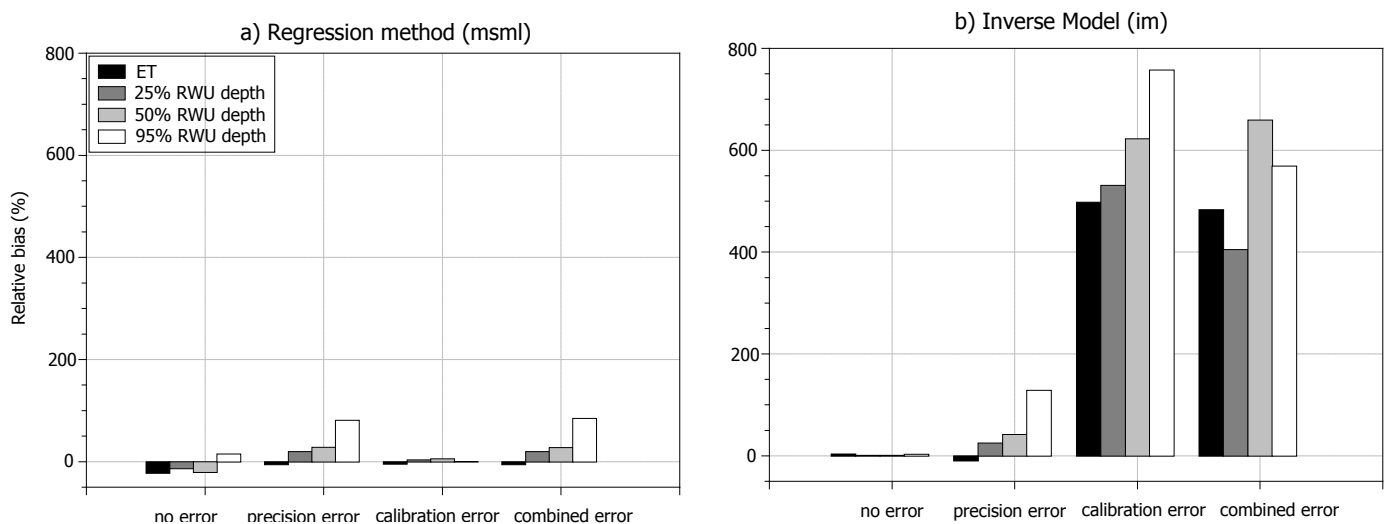

Figure 6. Comparison of the mean relative bias between synthetic and predicted values of evapotranspiration and the mean depths where $25,50,90 \%$ of water extraction occurs for soil moisture time series: without uncertainty (no error), precision uncertainty (precision error), calibration uncertainty (calibration error) and precision and calibration uncertainty (combined error) for the msml regression (a) and the im (b).

\section{Discussion}

We tested the application of several methods deriving, based on the soil water balance, how much water was extracted from the soil by evapotranspiration and how the extraction profile (sink term profile) changed with soil depth. The bases for all methods are time series of volumetric soil water content derived from measurements, although some methods require more information on soil properties, in particular the inverse model (im). None of the methods relies on a priori information on the shape of the sink term profile, nor do any of them make any assumptions on it being constant with time. This is the great advantage of these methods over others (Dardanelli et al., 2004; McIntyre et al., 1995; Hopmans and Bristow, 2002; Zuo et al., 2004). Since only changes in soil water content are considered, none of the investigated methods distinguish between soil evaporation and root water uptake. For the same reason, none of the water balance methods can be applied during times of fast soil water flow, for example during or after a rainfall event.

We used synthetic soil water content "observations" to validate the model results. This procedure has the great advantage that the "true" water flow and sink term profiles are perfectly known, including the nature of data uncertainty with regard to calibration error and sensor precision. However, our model only accounts for vertical matrix flow, notably neglecting horizontal heterogeneity, which may be an additional challenge for deriving evapotranspiration in real-world situations. Thus, additional tests of the methods in controlled field conditions, like with large lysimeters, and comparison with additional data, like isotope profiles, are necessary to confirm our results.

In the first part of the paper, we investigated how well all methods reproduced the sink term profile and total evapotranspiration when assuming that the measurements of soil water content were free of measurement errors, i.e., they were well calibrated and measured precisely. Even in this idealistic setting, the investigated methods performed very differently, most prominently depending on whether or not vertical flow could be accounted for by the method. The methods showing the greatest deviation between the "observed" (synthetic) evapotranspiration and sink term profiles were those not accounting for vertical flow within the soil (sssl and ssml methods). In those simpler soil water balance methods, any change in soil moisture is assigned only to root water uptake (Rasiah et al., 1992; Musters et al., 2000; Hupet et al., 2002). However, even several days after a rainfall event, the vertical matrix flow within the soil can be similar in magnitude to the root water uptake (Schwärzel et al., 2009), and this leads to considerable overestimation of the sink term when soil water flow is not accounted for. This error adds up when the sink term is integrated over depth and leads to a bias in the evapotranspiration estimate, which is the case for the ssml method.

This distinction between vertical soil water flow and water extraction is the major challenge when applying water balance methods, because these fluxes occur concurrently during daytime (Gardner, 1983; Feddes and Raats, 2004). The regression method (msml) avoids this problem by considering vertical soil water fluxes, estimated from change in soil water content during nighttime. $\mathrm{Li}$ et al. (2002) used a similar approach to derive transpiration and root water uptake patterns from soil moisture changes between different times of the day. This direct attribution of nighttime change in soil water content to soil water flow inherently assumes that both nighttime evapotranspiration and hydraulic redistribution are negligible. Li et al. (2002) measured nocturnal sap flow in order to ascertain that nighttime transpiration was insignificant. Also, in lysimeters, the weight changes can be used to validate the assumption. This assumption is the main drawback of this method, in contrast to the large advantage that it requires very limited input data, especially no a priori in- 
formation on soil properties. In contrast, the im approach inferred evapotranspiration and sink term patterns with greater quality when soil water content measurements were free of error. However, because our analysis uses model-generated time series of soil water content in order to mimic measurements, the soil properties of the original "experiment" are completely known, which is not usually the case in natural conditions. Usually, soil hydraulic parameters have to be estimated by means of a calibration procedure. This process is non-trivial and limited by the non-uniqueness of the calibrated parameters (Hupet et al., 2003), which results in uncertainties in simulated soil water fluxes and root water uptake rates (Duan et al., 1992; Musters and Bouten, 2000; Musters et al., 2000; Hupet et al., 2002, 2003). This reliance of the im approach on precise knowledge of the soil environment is the main drawback of that approach.

Several studies on estimation of root water uptake profiles focused on uncertainties related to calibrated parameters of soil and the root water uptake models (Musters and Bouten, 2000; Musters et al., 2000; Hupet et al., 2002, 2003). When data and models are used, uncertainties arise not from soil parameter uncertainty but in fact already evolve during the measurement process of the environmental data (Spank et al., 2013). Thus, in the second part of this paper, we investigated how measurement noise (precision), wrong sensor calibration (accuracy) and their combination reflect on the derivation of evapotranspiration and sink term patterns from soil water content measurements. We only performed this analysis for the two methods which performed satisfactorily without sensor errors: the msml regression method and the im. In this more realistic setting, the simpler regression method (msml) performed much better than the im. The latter was strongly affected by inaccurate or lack of site-specific calibration. This "calibration error" renders the evolution of the vertical potential gradients and soil moisture profile inconsistent with the evolution of the vertical sink term distribution, and thus introduces grave overestimation of root water uptake and evapotranspiration for the considered time steps (Fig. S2). Generally, the prediction of the im improves when longer evaluation periods are considered (cf. Zuo and Zhang, 2002), and therefore the calibration error may become less prominent when considering time steps of several days as done in Zuo and Zhang (2002). Compared to the effect of calibration, the sensor precision had a much smaller effect. Thus, the im may be applicable and should be tested in situations where all sensors in the profile are well calibrated. A further improvement of the im could be achieved by smoothing the measured soil water content profiles via a polynomial function to get an accurate and continuous distribution of soil water contents as done in Li et al. (2002) and Zuo and Zhang (2002).

The msml regression model was overall more robust towards the investigated measurement errors. It was barely affected by calibration error but was somewhat affected by sensor precision. This is expected, since the sensor calibration only improves the absolute values of the measurements, and does not affect the course of the soil moisture desiccation. The case is different for uncertainty due to sensor precision, which results in higher deviations between observed and predicted sink term uptake patterns (Fig. 6). As this method uses linear regression on the temporal evolution of soil water contents, the quantity of root water uptake depends on the gradient of the slopes. Those slopes are strongly influenced by the random scatter of data points, which is characteristic for sensor noise. Using the smallest time step of $1 \mathrm{~h}$, we could estimate the relative depth where $50 \%$ of water extraction occurs with a bias less than $30 \%$. Using higher time resolution with several measurements per hour or several minutes and noise-reducing filters (Li et al., 2002; Peters et al., 2013) would likely further improve this result. This method should be further evaluated with lysimeters in order to test its application in controlled but more realistic environments.

Furthermore, our study demonstrates that measured soil moisture time series already include information on evapotranspiration and root water uptake patterns. This has already been stated by Musters and Bouten (2002) as well as Zuo and Zhang (2002). Contrary to these studies, where only temporal resolutions of 1 day or more are investigated, we additionally looked at measurement time intervals in the range of hours. Our results confirm that different methods require measurements with different temporal resolutions. The more simple msml regression model showed better applicability for measurements taken with an interval less than $6 \mathrm{~h}$. These results are similar to Breña Naranjo et al. (2011) for a water balance method. The higher time resolution better reflects the temporal change in evapotranspiration, which may be considerable over the course of a day (Jackson et al., 1973). Conversely, the im works better for coarser temporal resolution for the case that soil water content measurements are error-free. If a possible measurement error is considered, coarser temporal resolutions are also better suitable to estimate evapotranspiration and root water uptake. With a higher temporal resolution (here 1 day instead of several hours) the total evapotranspiration and sink term also increases (integrated over the entire time). Therefore, the iteration of the im procedure could determine the sink term with a higher accuracy.

Another important prerequisite besides temporal resolution of the soil moisture time series is the adequate number of soil moisture measurements over the entire soil column to well capture the very nonlinear depth profile of water removal from the soil. This becomes most obvious when comparing the results from the simple single-layer water balance method (sssl) with the multi-layer ( $\mathrm{ssml}$ ) one. The prediction of the single-layer model is dominated by the specific depth at which the single sensor is located, and how much it is affected by root water uptake. In the presented case it strongly underestimated overall evapotranspiration because it observes only one part of the sink term profile and omits both the much more elevated uptake in the top soil and the deep uptake below the measurement depth. In contrast to 
that, the multi-layer method reproduces better the time series of evapotranspiration, because it samples the uptake profiles more holistically. Similarly, Schwärzel et al. (2009) and Clausnitzer et al. (2011) also found that high spatial resolution of water content sensors allow for a more reliable determination of evapotranspiration. Important consideration should be given to the very shallow soil depths, representative of the pure soil evaporation process $(z<5 \mathrm{~cm})$, which are notoriously undersampled due to technical limitations. This may lead to underestimation of evaporation and therefore evapotranspiration in all investigated water balance applications.

Our results show that water balance methods have potential to be applied for derivation of water extraction profiles, but they also suggest that their application may be challenging in realistic conditions. In particular, im has great potential, in theory, but obtaining information of the soil environment with sufficient accuracy may be unrealistic. The msml regression method is particularly promising, as it requires little input and is comparably robust towards measurement errors. Further tests in controlled environments and ideally in concert with isotope studies should be conducted to further test the application of these methods in real-world conditions.

The great advantage of all considered methods is that they do not require a priori information about total evapotranspiration or the shape of the root water uptake profiles. Root water uptake moves up or down depending on soil water status (Lai and Katul, 1998; Li et al., 2002, Doussan et al., 2006; Garrigues et al., 2006), and many existing approaches are unable to account for this dynamic of root water uptake. Root water extraction profiles are central topics in ecological and ecohydrological research on resource partitioning (e.g., Ogle et al., 2004; Leimer et al., 2014; Schwendenmann et al., 2014) and drivers for ecosystem structure (Arnold et al., 2010). Water balance methods are potential tools for comparing those extraction profiles between sites and thus contributing to ecohydrological process understanding.

\section{Conclusions}

The aim of this study was to evaluate four water balance methods of differing complexity to estimate sink term profiles and evapotranspiration from volumetric soil water content measurements. These methods do not require any a priori information of root distribution parameters, which is the advantage compared to common root water uptake models. We used artificial data of soil moisture and sink term profiles to compare the quality of the estimates of those four methods. Our overall comparison involved the examination of the impact of measurement frequency and model intricacy, as well as the uncertainties of soil moisture sensors on predicting sink term profiles. For the selected dry period of 33 days and under consideration of possible measurement un- certainties the multi-step, multi-layer (msml) regression obtained the best estimation of sink term patterns. In general, the predictions with the four data-driven methods show that these methods have different requirements on the measurement frequency of soil moisture time series and on additional input data like precipitation and soil hydraulic parameters. Further, we were able to show that the more complex methods like the msml regression and the inverse model (im) predict evapotranspiration and the sink term distribution more accurately than the simpler single-step, single-layer (sssl) water balance and the single-step, multi-layer (ssml) water balance.

Unfortunately, the estimations of the im are strongly influenced by the uncertainty of measurements. Moreover, numerical soil water flow models like the im require a large amount of prior information (e.g., boundary conditions, soil hydraulic parameters) which is usually not available in sufficient quality. For example, the soil hydraulic parameters have to be calibrated before use, which introduces additional uncertainties in the parameter sets. It is important to keep this in mind while comparing the im with the $\mathrm{msml}$ regression model, especially in light of the influence of measurement uncertainties.

Our results show that highly resolved (temporal and spatial) soil water content measurements contain a great deal of information which can be used to estimate the sink term when the appropriate approach is used. However, we acknowledge that this study using numerical simulations is only a first step towards the application on real field measurements. The msml regression model has to be tested with real field data, especially with lysimeter experiments. Lysimeters allow for closing of the water balance and validation with measured evapotranspiration, while soil water content measurements can be conducted in a similar way to field experiments. With such experiments, the proposed method can be evaluated in an enhanced manner. 


\section{Appendix A}

Table A1. Nomenclature.

\begin{tabular}{|c|c|}
\hline$b$ & relative bias $(\%)$ \\
\hline$d_{t}$ & length of active transpiration period over a day $(\mathrm{h})$ \\
\hline$d_{z, i}$ & thickness of soil layer $i(\mathrm{~m})$ \\
\hline DOY & day of year \\
\hline$e$ & difference in observed and estimated soil water content in the inverse model \\
\hline$E$ & evapotranspiration $\left(\mathrm{mm} \mathrm{h}^{-1}\right.$ or $\left.\mathrm{cm} \mathrm{d}^{-1}\right)$ \\
\hline$E_{\mathrm{S}}$ & bare soil evaporation $\left(\mathrm{mm} \mathrm{h}^{-1}\right)$ \\
\hline$E_{\mathrm{t}}$ & transpiration $\left(\mathrm{mm} \mathrm{h}^{-1}\right)$ \\
\hline$\widetilde{E}$ & estimated evapotranspiration $\left(\mathrm{mm} \mathrm{h}^{-1}\right)$ \\
\hline$h$ & soil matric potential $(\mathrm{m})$ \\
\hline$i$ & soil layer index \\
\hline$j$ & time step index \\
\hline$K(h)$ & hydraulic conductivity $\left(\mathrm{m} \mathrm{s}^{-1}\right)$ \\
\hline$K_{\text {sat }}$ & saturated hydraulic conductivity $\left(\mathrm{m} \mathrm{s}^{-1}\right)$ \\
\hline$m_{\text {tot }}$ & slope of fitted linear function on $\theta(t)$ \\
\hline$m_{\text {extr }}$ & slope of fitted linear function on $\theta(t)$ due to sink term \\
\hline$m_{\text {flow }}$ & slope of fitted linear function on $\theta(t)$ due to vertical soil water flow \\
\hline$n_{\mathrm{vG}}$ & van Genuchten parameter $(-)$ \\
\hline NSE & Nash-Sutcliffe efficiency criterion \\
\hline$P$ & precipitation $\left(\mathrm{mm} \mathrm{h}^{-1}\right)$ \\
\hline$q$ & percolation $\left(\mathrm{mm} \mathrm{h}^{-1}\right)$ \\
\hline RV & relative variability \\
\hline$S$ & sink term in Richards equation $\left(\mathrm{s}^{-1}\right)$ \\
\hline$S_{i}$ & discretized sink term in the soil layer $i\left(\mathrm{~m} \mathrm{~s}^{-1}\right)$ \\
\hline$\tilde{S}$ & estimated sink term $\left(\mathrm{m} \mathrm{s}^{-1}\right)$ \\
\hline$s$ & standard deviation \\
\hline$t$ & time $(s)$ \\
\hline$\Delta t$ & time step $(\mathrm{h})$ \\
\hline$v$ & iteration step number $(-)$ \\
\hline $\bar{x}$ & mean value \\
\hline$x$ & observed (synthetic) value \\
\hline$\tilde{x}$ & estimated values \\
\hline$z$ & vertical coordinate $(\mathrm{m})$ \\
\hline$z_{r}$ & active rooting depth $(\mathrm{cm})$ \\
\hline$z_{25 \%}$ & depth up to which $25 \%$ of root water uptake occurs $(\mathrm{cm})$ \\
\hline$z_{50 \%}$ & depth up to which $50 \%$ of root water uptake occurs $(\mathrm{cm})$ \\
\hline$z_{90 \%}$ & depth up to which $90 \%$ of root water uptake occurs $(\mathrm{cm})$ \\
\hline$\alpha$ & van Genuchten parameter $\left(\mathrm{m}^{-1}\right)$ \\
\hline$\theta$ & volumetric soil water content $\left(\mathrm{m}^{3} \mathrm{~m}^{-3}\right)$ \\
\hline$\theta_{\mathrm{r}}$ & residual volumetric soil water content $\left(\mathrm{m}^{3} \mathrm{~m}^{-3}\right)$ \\
\hline$\underbrace{}_{\mathrm{s}}$ & saturated volumetric soil water content $\left(\mathrm{m}^{3} \mathrm{~m}^{-3}\right)$ \\
\hline$\widetilde{\theta}$ & estimated volumetric soil water content $\left(\mathrm{m}^{3} \mathrm{~m}^{-3}\right)$ \\
\hline$\Delta \theta$ & deviation in volumetric soil water content over time $\left(\mathrm{m}^{3} \mathrm{~m}^{-3}\right)$ \\
\hline$\varepsilon \mathrm{ZZ}$ & decision criterion for termination of the iteration process (inverse model from Zuo and Zhang, 2002) \\
\hline$\varepsilon_{\mathrm{GH}, i}$ & decision criterion for termination of the iteration process in the inverse model proposed here \\
\hline
\end{tabular}




\section{The Supplement related to this article is available online at doi:10.5194/hess-12-409-2015-supplement.}

Acknowledgements. Financial support through the "ProExzellenz" Initiative from the German federal state of Thuringia to the Friedrich Schiller University Jena within the research project AquaDiva@Jena for conducting the research is gratefully acknowledged. This work was also financially supported by the Deutsche Forschungsgemeinschaft (DFG) within the project "The Jena Experiment". M. Guderle was also supported by the International Max Planck Research School for Global Biogeochemical Cycles (IMPRS-gBGC). We thank the editor, Nadia Ursino, for handling the manuscript and the two anonymous referees for their helpful comments. We also thank Maik Renner, Kristin Bohn, and Marcel Bechmann for fruitful discussions on an earlier version of this manuscript.

The service charges for this open access publication have been covered by the Max Planck Society.

Edited by: N. Ursino

\section{References}

Allen, R. G., Pereira, L. S., Raes, D., and Smith, M.: Crop evapotranspiration: Guidelines for computing crop requirements, FAO Irrigation and Drainage Paper No. 56, FAO, Rome, Italy, 1998.

Arnold, S., Attinger, S., Frank, K., and Hildebrandt, A.: Uncertainty in parameterisation and model structure affect simulation results in coupled ecohydrological models, Hydrol. Earth Syst. Sci., 13, 1789-1807, doi:10.5194/hess-13-1789-2009, 2009.

Asbjornsen, H., Goldsmith, G. R., Alvarado-Barrientos, M. S., Rebel, K., Van Osch, F. P., Rietkerk, M., Chen, J., Gotsch, S., Tobón, C., Geissert, D. R., Gómez-Tagle, A., Vache, K., and Dawson, T. E.: Ecohydrological advances and applications in plant-water relations research: a review, J. Plant Ecol., 4, 3-22, doi:10.1093/jpe/rtr005, 2011.

Bechmann, M., Schneider, C., Carminati, A., Vetterlein, D., Attinger, S., and Hildebrandt, A.: Effect of parameter choice in root water uptake models - the arrangement of root hydraulic properties within the root architecture affects dynamics and efficiency of root water uptake, Hydrol. Earth Syst. Sci., 18, 4189-4206, doi:10.5194/hess-18-4189-2014, 2014.

Breña Naranjo, J. A., Weiler, M., and Stahl, K.: Sensitivity of a data-driven soil water balance model to estimate summer evapotranspiration along a forest chronosequence, Hydrol. Earth Syst. Sci., 15, 3461-3473, doi:10.5194/hess-15-3461-2011, 2011.

Chanzy, A., Gaudu, J. C., and Marloie, O.: Correcting the temperature influence on soil capacitance sensors using diurnal temperature and water content cycles (Basel, Switzerland), Sensors, 12, 9773-9790, doi:10.3390/s120709773, 2012.

Chapin, F. S., Matson, P. A., and Mooney H. A.: Principles of Terrestrial Ecosystem Ecology, Springer-Verlag, New York, ISBN 0-387-95439-2, 2002.
Clausnitzer, F., Köstner, B., Schwärzel, K., and Bernhofer, C.: Relationships between canopy transpiration, atmospheric conditions and soil water availability - Analyses of long-term sapflow measurements in an old Norway spruce forest at the Ore Mountains/Germany, Agr. Forest Meteorol.,151, 1023-1034, doi:10.1016/j.agrformet.2011.04.007, 2011.

Clothier, B. E. and Green, S. R.: Rootzone processes and the efficient use of irrigation water, Agr. Water Manage., 25, 1-12, doi:10.1016/0378-3774(94)90048-5, 1994.

Coelho, F. and Or, D.: A parametric model for two-dimensional water uptake intensity by corn roots under drip irrigation, Soil Sci Soc. Am. J., 60, 1039-1049, 1996.

Dardanelli, J. L., Ritchie, J. T., Calmon, M., Andriani, J. M., and Collino, D. J.: An empirical model for root water uptake, Field Crops Res., 87, 59-71, doi:10.1016/j.fcr.2003.09.008, 2004.

Davis, S. D. and Mooney, H. A.: Water use patterns of four co-occurring chaparral shrubs, Oecologia, 70, 172-177, doi:10.1007/BF00379236, 1986.

Doussan, C., Pierret, A., Garrigues, E., and Pagès, L.: Water uptake by plant roots: II - Modelling of water transfer in the soil root-system with explicit account of flow within the root system - Comparison with experiments, Plant Soil, 283, 99-117, doi:10.1007/s11104-004-7904-z, 2006.

Duan, Q., Sorooshian, S., and Gupta, V.: Effective and Efficient Global Optimization for Conceptual Rainfall-Runoff Models, Water Resour. Res., 28, 1015-1031, 1992.

Feddes, R. A. and Raats, P. A. C.: Parameterizing the soil-waterplant root system, in: Unsaturated-zone Modeling: Progress, Challenges and Applications, edited by: Feddes, R. A., de Rooij, G. H., and van Dam, J. C., Kluwer Academic Publishers, Dordrecht, the Netherlands, 95-141, 2004.

Feddes, R. A., Hoff, H., Bruen, M., Dawson, T., De Rosnay, P., Dirmeyer, P., Jackson, R. B., Kabat, P., Kleidon, A., Lilly, A., and Pitman, A. J.: Modeling root water uptake in hydrological and climate models, B. Am. Meteorol. Soc., 82, 2797-2809, 2001.

Gale, M. R. and Grigal, D. K.: Vertical root distributions of northern tree species in relation to successional status, Can. J. For. Res., 17, 829-834, 1987.

Gardner, W. R.: Soil properties and efficient water use: An overview, in: Limitations to efficient water use in crop production, edited by: Taylor, H. M., Jordan, W. R., and Sinclair, T. S., ASA-CSSA-SSSA, Madison, USA, 45-64, 1983.

Garrigues, E., Doussan, C., and Pierret, A.: Water Uptake by Plant Roots: I - Formation and Propagation of a Water Extraction Front in Mature Root Systems as Evidenced by 2D Light Transmission Imaging, Plant Soil, 283, 83-98, doi:10.1007/s11104-004-79030,2006

Green, S. R. and Clothier, B. E.: Root water uptake by kiwifruit vines following partial wetting of the root zone, Plant Soil, 173, 317-328, 1995.

Green, S. R. and Clothier, B. E.: The root zone dynamics of water uptake by a mature apple tree, Plant Soil, 206, 61-77, 1999.

Gupta, H. V., Kling, H., Yilmaz, K. K., and Martinez, G. F.: Decomposition of the mean squared error and NSE performance criteria: Implications for improving hydrological modelling, J. Hydrol., 377, 80-91, doi:10.1016/j.jhydrol.2009.08.003, 2009.

Hamblin, A. and Tennant, D.: Root length density and water uptake in cereals and grain legumes: how well are they correlated?, Aust. J. Agr. Res., 38, 513-527, doi:10.1071/AR9870513, 1987. 
Hildebrandt, A. and Eltahir, E. A. B.: Ecohydrology of a seasonal cloud forest in Dhofar: 2. Role of clouds, soil type, and rooting depth in tree-grass competition, Water Resour. Res., 43, 1-13, doi:10.1029/2006WR005262, 2007.

Hopmans, J. W. and Bristow, K. L.: Current capabilities and future needs of root water and nutrient uptake modeling, Adv. Agron., 77, 104-175, 2002.

Hupet, F., Lambot, S., Javaux, M., and Vanclooster, M.: On the identification of macroscopic root water uptake parameters from soil water content observations, Water Resour. Res., 38, 1-14, doi:10.1029/2002WR001556, 2002.

Jackson, R. B., Candell, J., Ehleringer, J. R., Mooney, H. A., Sala, O. E., and Schulze, E. D.: A global analysis of root distributions for terrestrial biomes, Oecologia, 108, 389-411, 1996.

Jackson, R. B., Sperry, J. S., and Dawson, T. E.: Root water uptake and transport: using physiological processes in global predictions, Trends Plant Sci., 5, 482-488, 2000.

Jackson, R. D., Kimball, B. A., Reginato, R. J., and Nakayama, F. S.: Diurnal soil-water evaporation: timedepth-flux patterns, Soil Sci. Soc. Am. Pro., 37, 505-509, doi:10.2136/sssaj1973.03615995003700040014x, 1973.

Khalil, M., Sakai, M., Mizoguchi, M., and Miyazaki, T.: Current and prospective applications of Zero Flux Plane (ZFP) method, J. Jpn. Soc. Soil Phys., 95, 75-90, 2003.

Kollet, S. J.: Influence of soil heterogeneity on evapotranspiration under shallow water table conditions: transient, stochastic simulations, Environ. Res. Lett., 4, 035007, doi:10.1088/17489326/4/3/035007, 2009.

Kosugi, Y. and Katsuyama, M.: Evapotranspiration over a Japanese cypress forest, II. Comparison of the eddy covariance and water budget methods, J. Hydrol., 334, 305-311, 2007.

Kuhlmann, A., Neuweiler, I., van der Zee, S. E. A. T. M., and Helmig, R.: Influence of soil structure and root water uptake strategy on unsaturated flow in heterogeneous media, Water Resour. Res., 48, W02534, doi:10.1029/2011WR010651, 2012.

Lai, C. T. and Katul, G.: The dynamic role of root-water uptake in coupling potential to actual transpiration, Adv. Water Resour., 23, 427-439, doi:10.1016/S0309-1708(99)00023-8, 2000.

Lee, A.: Movement of water through plants, Pract. Hydropon. Greenhous., 50, GRODAN, http://www.grodan.com/files/ Grodan/PG/Articles/2009/Movement_of_water_through_plants. pdf (last access: September 2014), 2009.

Leimer, S., Kreutziger, Y., Rosenkranz, S., Beßler, H., Engels, C., Hildebrandt, A., Oelmann, Y., Weisser, W. W., Wirth, C., Wilcke, W.: Plant diversity effects on the water balance of an experimental grassland, Ecohydrol., 7, 1378-1391, doi:10.1002/eco.1464, 2014.

Le Roux, X., Bariac, T., and Mariotti, A.: Spatial partitioning of the soil water resource between grass and shrub components in a West African humid savanna, Oecologia, 104, 147-155, 1995.

Li, K., Dejong, R., and Boisvert, J.: An exponential root-wateruptake model with water stress compensation, J. Hydrol., 252, 189-204, doi:10.1016/S0022-1694(01)00456-5, 2001.

Li, Y., Fuchs, M., Cohen, S., Cohen, Y., and Wallach, R.: Water uptake profile response of corn to soil, Plant Cell Environ., 25, 491-500, 2002.

Loheide, S. P.: A method for estimating subdaily evapotranspiration of shallow groundwater using diurnal water table fluctuations, Ecohydrology, 66, 59-66, doi:10.1002/eco.7, 2008.
Maruyama, A. and Kuwagata, T.: Diurnal and seasonal variation in bulk stomatal conductance of the rice canopy and its dependence on developmental stage, Agr. Forest Meteorol., 148, 1161-1173, doi:10.1016/j.agrformet.2008.03.001, 2008.

McIntyre, B. D., Riha, S. J., and Flower, D. J.: Water uptake by pearl millet in a semiarid environment, Field Crop. Res., 43, 6776, 1995.

Musters, P. A. D. and Bouten, W.: Assessing rooting depths of an austrian pine stand by inverse modeling soil water content maps, Water Resour. Res., 35, 3041, doi:10.1029/1999WR900173, 1999.

Musters, P. A. D. and Bouten, W.: A method for identifying optimum strategies of measuring soil water contents for calibrating a root water uptake model, J. Hydrol., 227, 273-286, doi:10.1016/S0022-1694(99)00187-0, 2000.

Musters, P. A. D., Bouten, W., and Verstraten, J. M.: Potentials and limitations of modelling vertical distributions of root water uptake of an Austrian pine forest on a sandy soil, Hydrol. Process., 14, 103-115, 2000.

Ogle, K., Wolpert, R. L., and Reynolds, J. F.: Reconstructing plant root area and water uptake profiles, Ecology, 85, 1967-1978, 2004.

Peters, A., Nehls, T., Schonsky, H., and Wessolek, G.: Separating precipitation and evapotranspiration from noise - a new filter routine for high-resolution lysimeter data, Hydrol. Earth Syst. Sci., 18, 1189-1198, doi:10.5194/hess-18-1189-2014, 2014.

Plamboeck, A. H., Grip, H., and Nygren, U.: A hydrological tracer study of water uptake depth in a Scots pine forest under two different water regimes, Oecologia, 119, 452-460, 1999.

Rasiah, V., Carlson, G. C., and Kohl, R. A.: Assessment of functions and parameter estimation methods in root water uptake simulation, Soil Sci. Soc. Am., 56, 1267-1271, 1992.

Ravenek, J. M., Bessler, H., Engels, C., Scherer-Lorenzen, M., Gessler, A., Gockele, A., De Luca, E., Temperton, V. M., Ebeling, A., Roscher, C., Schmid, B., Weisser, W. W., Wirth, C., de Kroon, H., Weigelt, A., and Mommer, L.: Long-term study of root biomass in a biodiversity experiment reveals shifts in diversity effects over time, Oikos, 000, 1-9, doi:10.1111/oik.01502, 2014.

Roscher, C., Scherer-Lorenzen, M., Schumacher, J., Temperton, V. M., Buchmann, N., and Schulze, E. D.: Plant resource-use characteristics as predictors for species contribution to community biomass in experimental grasslands, Perspect. Plant Ecol., 13, 1-13, doi:10.1016/j.ppees.2010.11.001, 2011.

Ross, P. J.: Modeling soil water and solute transport - fast, simplified numerical solutions, Am. Soc. Agron., 95, 1352-1361, 2003.

Ross, P. J.: Fast Solution of Richards' Equation for Flexible Soil Hydraulic Property Descriptions, Land and Water Technical Report, CSIRO, 39/06, 2006.

Sánchez, C., Fischer, G., and Sanjuanelo, D. W.: Stomatal behavior in fruits and leaves of the purple passion fruit (Passiflora edulis Sims) and fruits and cladodes of the yellow pitaya [Hylocereus megalanthus (K. Schum ex Vaupel) Ralf Bauer], Agronomía Colombiana, 31, 38-47, 2013.

Schaap, M. G., Leij, F. J., and van Genuchten, M. T.: Rosetta: a computer program for estimating soil hydraulic parameters with hierarchical pedotransfer functions, J. Hydrol., 251, 163-176, doi:10.1016/S0022-1694(01)00466-8, 2001. 
Schenk, H. J.: The shallowest possible water extraction profile: a null model for global root distributions, Vadose Zone J., 7, 11191124, doi:10.2136/vzj2007.0119, 2008.

Schneider, C. L., Attinger, S., Delfs, J.-O., and Hildebrandt, A.: Implementing small scale processes at the soil-plant interface - the role of root architectures for calculating root water uptake profiles, Hydrol. Earth Syst. Sci., 14, 279-289, doi:10.5194/hess14-279-2010, 2010.

Schume, H., Hager, H., and Jost, G.: Water and energy exchange above a mixed European Beech - Norway Spruce forest canopy: a comparison of eddy covariance against soil water depletion measurement, Theor. Appl. Climatol., 81, 87-100, 2005.

Schwärzel, K., Menzer, A., Clausnitzer, F., Spank, U., Häntzschel, J., Grünwald, T., Köstner, B., Bernhofer, C., and Feger, K. H.: Soil water content measurements deliver reliable estimates of water fluxes: a comparative study in a beech and a spruce stand in the Tharandt forest (Saxony, Germany), Agr. Forest Meteorol., 149, 1994-2006, doi:10.1016/j.agrformet.2009.07.006, 2009.

Schwendenmann, L., Pendall, E., Sanchez-Bragado, R., Kunert, N., and Hölscher, D.: Tree water uptake in a tropical plantation varying in tree diversity: interspecific differences, seasonal shifts and complementarity, Ecohydrology, doi:10.1002/eco.1479, online first, 2014.

Seneviratne, S. I., Corti, T., Davin, E. L., Hirschi, M., Jaeger, E. B., Lehner, I., Orlowsky, B., and Teuling, A. J.: Investigating soil moisture-climate interactions in a changing Climate: a review, Earth-Sci. Rev., 99, 125-161, doi:10.1016/j.earscirev.2010.02.004, 2010.

Spank, U., Schwärzel, K., Renner, M., Moderow, U., and Bernhofer, C.: Effects of measurement uncertainties of meterological data on estimates of site water balance components, J. Hydrol., 492, 176-189, 2013.

Teuling, A. J., Uijlenhoet, R., Hupet, F., and Torch, P. A.: Impact of water uptake strategy on soil moisture and evapotranspiration dynamics during drydown, Geophys. Res. Lett., 33, L03401, doi:10.1029/2005GL025019, 2006a.
Teuling, A. J., Seneviratne, S. I., Williams, C., and Torch, P. A.: Observed timescales of evapotranspiration response to soil moisture, Geophys. Res. Lett., 33, L23403, doi:10.1029/2006GL028178, 2006b.

van Genuchten, M. T.: A closed-form equation for predicting the hydraulic conductivity of unsaturated soils, Soil Sci. Soc. Am. J., 44, 892-898, 1980.

Verhoef, A., Fernández-Gálvez, J., Diaz-Espejo, A., Main, B. E., and El-Bishti, M.: The diurnal course of soil moisture as measured by various dielectric sensors: effects of soil temperature and the implications for evaporation estimates, J. Hydrol., 321, 147-162, doi:10.1016/j.jhydrol.2005.07.039, 2006.

Vrugt, J. A., van Wijk, M. T., Hopmans, J. W., and Šimunek, J.: One-, two-, and three-dimensional root water uptake functions for transient modeling, Water Resour. Res., 37, 2457, doi:10.1029/2000WR000027, 2001.

Wilson, K. B., Hanson, P. J., Mulholland, P. J., Baldocchi, D. D., and Wullschleger, S. D.: A comparison of methods for determining forest evapotranspiration and its components: sap-flow, soil water budget, eddy covariance and catchment water balance, Agr. Forest Meteorol., 106, 153-168, 2001.

Zuo, Q. and Zhang, R.: Estimating root-water-uptake using an inverse method, Soil Sci., 167, 561-571, 2002.

Zuo, Q., Meng, L., and Zhang, R.: Simulating soil water flow with root-water-uptake applying an inverse method, Soil Sci., 169, 13-24, doi:10.1097/01.ss.0000112018.97541.85, 2004.

Zwieniecki, M. A., Thompson, M. V., and Holbrook, N. M.: Understanding the Hydraulics of Porous Pipes: Tradeoffs Between Water Uptake and Root Length Utilization, J. Plant Growth Regul., 21, 315-323, 2003. 